\title{
70 Anos da Declaração Universal dos Direitos Humanos: Perspectivas Críticas - ENTREVISTA COM José J. QueIROZ
}

ReSUMO

Professor emérito da Universidade Católica de São Paulo (PUC-SP) e um dos nomes mais celebrados no campo da pósgraduação em “Ciência da Religião”, José J. Queiroz foi também um militante contumaz na luta pelos Direitos Humanos no Brasil. Sua trajetória docente, religiosa, militante e de vida constitui-se numa constelação de ações marcantes e inspiradoras na seara da valorização da vida humana e do respeito à diversidade em todos os seus matizes. Em especial, sua trajetória profissional relacionada à defesa dos direitos humanos, às vicissitudes desses direitos no mundo atual e à importância da educação para que os direitos humanos sejam entendidos, respeitados e praticados é hoje uma trilha a ser estudada e melhor conhecida por quem atua também nessa mesma senda humanista. Ao lado de outros líderes também devotados à luta pelos direitos dos seres humanos, como o também celebrado religioso Dom Paulo Evaristo Arns, José J. Queiroz dedicou-se ainda a refletir e a escrever sobre o contemporâneo - seus símbolos, sua complexidade e idiossincrasias. Doutor em Direito Canônico pela PontificiaStudiorumUniversitas A. S. Thoma Aq. im Urbe, mestre em Teologia e graduado em Direito e Filosofia, a produção teórica de José J. Queiroz aborda, ainda, e como não poderia deixar de ser, a ética - ou a falta dela - no contemporâneo. Seus livros "A Ética no Mundo de Hoje", "A Educação Popular nas Comunidades Eclesiais de Base" e "A Religiosidade do Povo" - todos publicados pelas Edições Paulinas - são hoje, entre outros livros de sua autoria, leitura obrigatória a todos os que, ocupados e preocupados com a educação popular e com a educação para os Direitos Humanos, dedicam-se a conhecer com mais profundidade essa importante temática. Nesta entrevista que ora se apresenta ao leitor, José J. Queiroz nos expõe um pouco mais de perto o que pensa acerca do contemporâneo e sobre o respeito ao Direitos Humanos no Brasil e no mundo, à medida que - também - nos instiga e nos anima a seguir lutando sempre por eles e por aqueles que, na contemporaneidade, deles mais necessitam - os oprimidos.

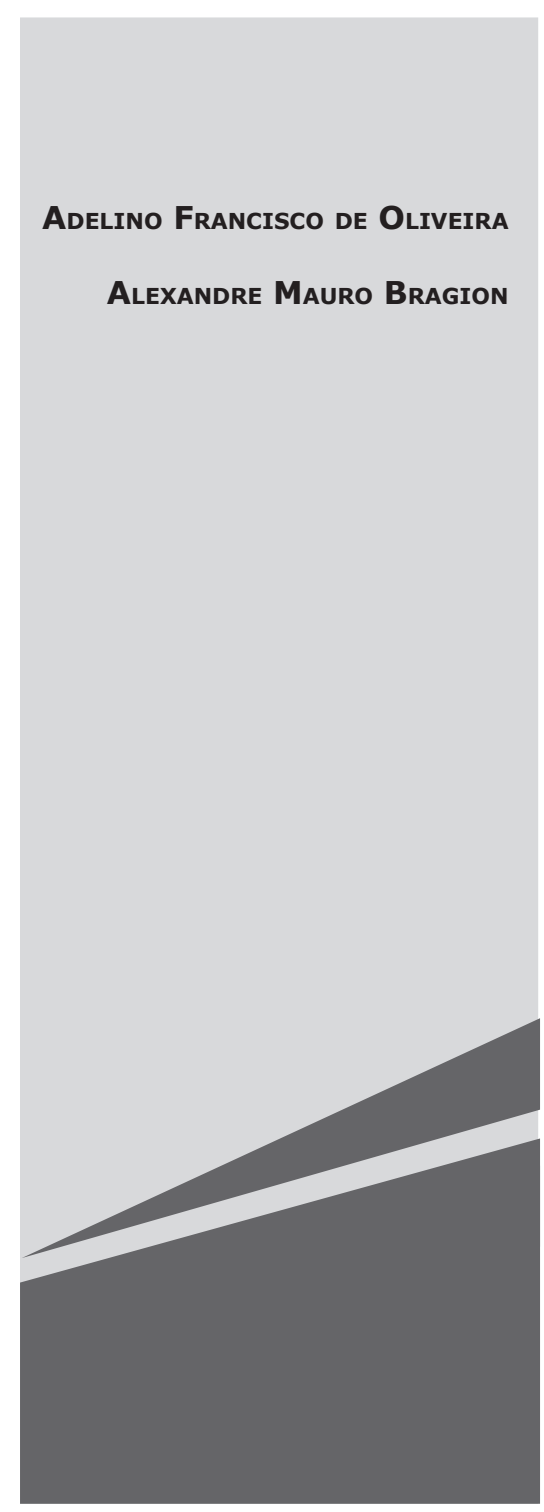


IMPULSO - Fale um pouco sobre sua formação e trajetória acadêmica.

Nasci em Salto Grande/SP, em 1932. Cursei o Ensino Médio (ginásio e colegial) no Seminário Dominicano Santa Catarina de Sena, em Santa Cruz do Rio Pardo (interior de São Paulo) e minha formação superior em filosofia e teologia se deu na Universidade dos Dominicanos em Bolonha (Itália), de 1958 a 1966. Naquele período, debrucei-me sobre a História da Filosofia, aprofundei-me na Filosofia Tomista, e terminei com uma dissertação de conclusão de curso para a obtenção do título de professor (Lector) que versava sobre La causalitàstrumentale el'ispirazione bíblica secondo San Tommaso D’Aquino. Meu doutorado se realizou em Roma na Universidade Santo Tomás de Aquino (Angelicum) de 1956 a 1960, onde defendi a tese De lurisdictione ad Confessionesaudiendas in lureOrdinisPraedicatorum (no período de 1216 a 1566). No Brasil, lecionei filosofia na Universidade Franciscana de São Paulo e Teologia e Direito Canônico na Faculdade Dominicana de São Paulo. Hoje, sou Professor Emérito da Universidade Católica de São Paulo atuando na pós-graduação em Ciência da Religião.

\section{IMPULSO - Qual a relevância dos Direitos Hu-} manos para o contemporâneo?

Os Direitos Humanos e sua Declaração de 1948, adotada pelas Nações Unidas, constituem em todos os seus parágrafos, um ideal comum a ser atingido por todos os povos e todas as nações em todas as épocas. A Declaração foi emanada considerando que o desconhecimento e o desprezo dos direitos do homem conduziram a atos de barbárie que revoltam a consciência da humanidade e também que o advento de um mundo em que os seres humanos sejam livres de falar e de crer libertos do terror e da miséria, foi proclamado como a mais alta inspiração do homem. Também motivou a Declaração a consideração de que é essencial a proteção dos direitos do homem por meio de um regime de direito para que o homem não seja compelido a um supremo recurso à revolta contra a tirania e a opressão. Os autores da declaração julgaram essencial encorajar o desenvolvimento de relações amistosas entre as nações.

IMPULSO - Como o senhor compreende seu vínculo e militância no campo dos Direitos Humanos?

Compreendo meu vínculo e militância no campo dos Direitos Humanos como um serviço irrecusável de um professor altamente graduado visando especialmente os mais pobres e desfavorecidos. Ao longo de minha vida, sempre procurei atuar em prol da construção de uma sociedade edificada a partir do direito e da justiça. Isso inclui a defesa intransigente dos Direitos Humanos, a partir de uma opção preferencial pelos mais pobres.

IMPULSO - No contexto da ditadura militar, como assumiu a defesa dos Direitos Humanos?

No contexto da ditadura militar, assumi a defesa dos direitos humanos integrando, como assessor, a Comissão Justiça e Paz de São Paulo nos anos em que Dom Paulo Evaristo Arns exerceu a função de Arcebispo de São Paulo. Lembro-me que eu ia para as comunidades da periferia de São Paulo portando a Bíblia e a CLT. Naquele contexto, a leitura libertadora da Bíblia, a formação política e o conhecimento dos parcos direitos já eram uma atitude compreendida como subversiva. Mas nós éramos destemidos, em um tempo duro, de autoritarismo. Nossa ação não deixou de ser fundamental para o avanço do processo de redemocratização.

IMPULSO - Em sua trajetória de defesa aos direitos humanos, o senhor passou por algum tipo de perseguição?

Pessoalmente, nunca fui perseguido, mas sofri como membro da Comissão de Direitos Humanos da Arquidiocese todas as perseguições e calúnias que o governo de direita e seus sequazes moviam contra os chamados "cristãos progressistas".

IMPULSO - O senhor atuou com Dom Paulo Evaristo Arns? Como foi trabalhar com Dom Paulo? 
Nunca escrevi algo especificamente sobre Dom Paulo Evaristo Arns, mas muito conversei com ele e sobre ele e muito aprendi com sua vida e ensinamentos e feitos. Como professor do Programa de Estudos Pós-graduados em Ciência da Religião, tive ocasião de orientar uma tese que abordou os direitos humanos na sua ação pastoral, livro já publicado pelo aluno e pesquisador Jorge Miklos. Minha atuação com ele se deu enquanto era assessor da Comissão Justiça e Paz fundada e incrementada por ele. Trabalhar com Dom Paulo foi uma dádiva na minha vida.

IMPULSO - O senhor tem uma longa trajetória como professor de ética. Qual a relação entre a disciplina ética e os Direitos Humanos?

Fui muitos anos professor de Ética. Íntima e imprescindível é a relação entre a disciplina da ética e os direitos humanos, pois as duas coisas são inseparáveis. Os conceitos e debates em torno da ética não deixam de ser fundamentos para a concepção de direitos humanos.

IMPULSO - Qual a importância da Teologia da Libertação para os Direitos Humanos?

A Teologia da Libertação, trabalhada profundamente pelo teólogo e filósofo Leonardo Boff, é fonte e suporte dos Direitos Humanos.

IMPULSO - Neste ano comemoram-se os 70 anos da Declaração Universal dos Direitos Humanos. Em sua avaliação, qual a importância desse documento?

A Declaração Universal dos Direitos Humanos, que já completa 70 anos, em seus 30 artigos, foi e é de fundamental importância, pois proclama que o reconhecimento da dignidade frente a todos os membros da família humana e dos seus direitos e regras inaliená- veis constitui o fundamento da liberdade, da justiça e da paz no mundo.

IMPULSO - Quais os desafios de hoje para o campo dos Direitos Humanos?

Hoje, continuam desafiando os direitos humanos a profunda desigualdade social, a situação de penúria e desproteção dos mais pobres.

IMPULSO - Como o senhor entende os ataques que parte da própria população brasileira faz contra o exercício e a difusão dos Direitos Humanos?

Os Direitos Humanos são muitas vezes criticados e atacados pelo segmento dominante da população, eis que se veem ameaçados em seus privilégios, e combatem tudo o que lhes parece pôr em risco a acomodação.

IMPULSO - Como podemos contribuir para que os Direitos Humanos sejam entendidos, respeitados e colocados em prática? Estamos muito longe de uma consciência mais humana?

Como integrante de um corpo docente, acredito que a educação em todos os campos é a seara mais fértil e apropriada para uma eficaz contribuição para que os direitos humanos sejam entendidos, respeitados e colocados em prática. Infelizmente, sua compreensão, seu reconhecimento e observância universal e efetiva, seja entre os povos dos Estados, membros da ONU, seja entre os povos dos territórios sob sua sustentação, ainda exigem uma longa caminhada. A Declaração já é um documento traduzido em quase todas as línguas. O site oficial da Declaração informa a existência de 403 traduções disponíveis. Embora recentes, os ideais e valores dos Direitos Humanos contêm traços da história antiga e das crenças religiosas e culturais no mundo. 